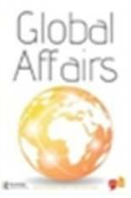

\title{
Learning in European Union peacebuilding: Rhetoric and reality
}

\begin{tabular}{|c|c|}
\hline Journal: & Global Affairs \\
\hline Manuscript ID & RGAF-2018-0023 \\
\hline Manuscript Type: & Research Article \\
\hline Keywords: & CFSP, CSDP, learning, foreign policy, security policy, peace building \\
\hline Abstract: & $\begin{array}{l}\text { The EU's growth as a security actor since } 2003 \text { has been closely } \\
\text { accompanied by the development of various learning mechanisms in order } \\
\text { to help improve the EU's performance in this realm. As most such } \\
\text { activities have involved civilian missions rather than military operations, } \\
\text { this article focuses on the learning culture underpinning the EU's civilian } \\
\text { conflict prevention and peacebuilding activities. This is especially critical as } \\
\text { the EU has increasingly framed these efforts in terms of adaptive and } \\
\text { ideational factors in host countries (training, mentoring, reform, advising, } \\
\text { capacity-building, resilience, etc.) rather than as 'interventions' whereby } \\
\text { the EU deploys its own resources to manage host country problems. In } \\
\text { other words, the EU is attempting to enhance the ability of host countries } \\
\text { to prevent or resolve conflicts on their own. However, it is also clear that } \\
\text { such efforts do not always produce the desired results in host countries, } \\
\text { especially in a crisis situation, and that the EU does not always follow its } \\
\text { own procedures regarding learning. Therefore despite considerable } \\
\text { progress since } 2003 \text { there is still much room for improvement in this } \\
\text { realm, along with a need for broader institutional reforms to improve the } \\
\text { EU's capabilities as a security actor. }\end{array}$ \\
\hline
\end{tabular}




\section{Learning in European Union peacebuilding: Rhetoric and reality}

The EU's growth as a security actor since 2003 has been closely accompanied by the development of various learning mechanisms in order to help improve the EU's performance in this realm. As most such activities have involved civilian missions rather than military operations, this article focuses on the learning culture underpinning the EU's civilian conflict prevention and peacebuilding activities. This is especially critical as the EU has increasingly framed these efforts in terms of adaptive and ideational factors in host countries (training, mentoring, reform, advising, capacity-building, resilience, etc.) rather than as 'interventions' whereby the EU deploys its own resources to manage host country problems. In other words, the EU is attempting to enhance the ability of host countries to prevent or resolve conflicts on their own. However, it is also clear that such efforts do not always produce the desired results in host countries, especially in a crisis situation, and that the EU does not always follow its own procedures regarding learning. Therefore despite considerable progress since 2003 there is still much room for improvement in this realm, along with a need for broader institutional reforms to improve the EU's capabilities as a security actor. 
Policy learning is a key area of increased EU activity in the realm of foreign/security policy and other policy domains as well as a central concept in the related academic literature. Within foreign and security policy in particular, in the past fifteen years the EU has devoted far more attention to processes of institutional learning and best practices than it had ever attempted between the 1970s and 1990s. Although EU foreign/security policy cooperation became more institutionalized, though not 'supranationalised' like EU economic policy, after the Maastricht Treaty on European Union (Øhrgaard 1997; Author 2003), the EU still struggled to cope with various external problems, particularly in the Balkans, though its new Common Foreign and Security Policy (CFSP). Further institutional reforms in this realm were undertaken by the late 1990 s to develop what is now known as the Common Security and Defence Policy (CSDP), while the EU has also paid far more attention to learning processes in order to take on a wider range of security-related tasks, such as conflict prevention/resolution, crisis management, and peacebuilding/peacekeeping.

This 'learning turn' in EU foreign/security policy is a consequence of two general factors: 1) foreign/security policy cannot be managed like socio-economic EU policy domains, in the form of forward-looking regulations and directives; and 2) EU member states still resist extensive delegation of certain responsibilities to centralised EU organisations such as the Commission and the European External Action Service (EEAS). These conditions are unlikely to change in the foreseeable future, which is why the EU continues to invest time and effort in social/networking/learning mechanisms and informal (as well as formal/legal) institution-building to improve its performance in this realm, while maintaining it as a decentralised policy sector still under the direct control of EU member states (i.e., more intergovernmental than supranational). ${ }^{1}$

\footnotetext{
${ }^{1}$ This approach has been termed 'new intergovernmentalism'; see Bickerton et al. 2015.
} 
The emergence of a learning culture within the realm of EU peacebuilding in particular offers researchers a unique opportunity to investigate how a complex organisation attempts to adapt itself in various ways to take on a wide range of new political tasks, some of which can be extremely risky. This objective has been built into several recent EU-funded research projects to help assess specific outcomes in the realm of peacebuilding with a view to improving the EU's performance in future endeavours. ${ }^{2}$ In this paper, I focus on the learning-related contributions of the EU-CIVCAP project in particular, beginning with an overview of how learning is defined and measured within the context of the EU's peacebuilding activities. ${ }^{3}$ In the second section, I highlight some of the major lessons identified by the other articles in this Forum (see also EU-CIVCAP 2018). In the third section I address some remaining challenges in this realm, in light of not just the major findings of EU-CIVCAP but also the EU's new ambitions as framed in its 2016 Global Strategy (HR/VP 2016) and other documents.

\section{Conceptualizing learning in EU peacebuilding}

Policy-relevant learning can be viewed most generally as a type of deliberate political reform, and should be distinguished from other related forms of change, such as vague 'lessons of history' (i.e., analogical reasoning) or mere 'adaptation' to new circumstances (Levitt \& March 1988; Levy 1994; Zito 2009; Zito \& Schout 2009). The purpose of policyrelevant learning on the part of the EU is to improve the fit between its existing institutional framework, organisational routines, and stated goals or ambitions, in this case involving peacebuilding. While analogical reasoning or adaptation efforts do not typically involve changes in core institutional values or purposes, learning can be conceptualised as a process

\footnotetext{
${ }^{2}$ In addition to EU-CIVCAP, these include EUCONRES, EUNPACK, IECEU, and WOSCAP (among others). ${ }^{3}$ In this article, peacebuilding is understood in broad terms as a range of activities aiming to reduce the risk of war (conflict prevention), address the roots of conflict, and promote sustainable peace (see for instance, Paris and Sisk, 2009).
} 
of deliberate, long-term, and highly self-reflexive institutional reform (Haas 1990). At a minimum, it consists of: 1) regularly benchmarking or reviewing EU policy performance in specific domains; 2) actively generating possible lessons as a result of the experience gained in undertaking new actions ('lessons identified'); 3) deliberately transforming lessons into policy-relevant knowledge through feedback/monitoring/training processes; and 4) institutionalising new knowledge ('lessons learned') for application to future operations, often in the form of (narrow) best practices, concepts, doctrines, and (broad) strategic plans.

Based on these processes, EU-CIVCAP researchers have attempted to identify examples of potential 'experiential institutional learning', defined as a need for changes in an institution's responsibilities/functions, rules/procedures, and resources/capabilities as a result of new information, observation, or experience. ${ }^{4}$ As we shall see in the next section, these examples take the form of specific 'lessons identified' regarding responsibilities, rules, and resources. ${ }^{5}$ By responsibilities we refer to the EU's own conception of its place in the world and the specific types of foreign/security policy activities (such as peacebuilding) that might reflect or advance its role. Although this articulation of the EU's responsibilities can be framed in terms of treaty articles and general strategic documents, EU-CIVCAP researchers have attempted to demonstrate this in far more specific terms regarding, for example, a CFSP/CSDP joint action (i.e., in terms of a 'mandate'). Changes in responsibilities as a result of experiential learning can be measured in three main ways: 1) an expansion and/or clarification of the initial mandate during the planning and/or implementation phases of a policy; 2) a change in the duration and/or geographic scope of a policy; and 3) the creation of complementary or follow-on policies in order to fulfil the original mandate and/or related policy goals, such as development or humanitarian assistance.

\footnotetext{
${ }^{4}$ For a more detailed discussion, see Author (2017a) and Author (2017b).

${ }^{5}$ It should be made clear that these are 'lessons identified' by EU-CIVCAP researchers and should be distinguished from the EU's own lessons observed, identified, or learned as generated by its internal procedures.
} 
By rules we refer to the regulations or principles governing a particular domain of activity, in this case the institutional structures and policymaking routines that guide the EU's peacebuilding activities as well as the more general relationship between this capacity and other major EU foreign policy initiatives, such as the European Neighbourhood Policy. As peacebuilding is not a distinct EU policy domain, it involves the ongoing coordination of a range of actors and institutions through the use of informal customs/norms and formal rules; these of course can also reflect, and possibly influence, how the EU determines future responsibilities and allocates resources to them. EU-CIVCAP researchers therefore attempt to identify a need for rule changes that could involve the modification of existing rules (including the role of various organisational actors) or the creation of entirely new ones in order to improve policy performance. Moreover, as the EU increasingly works with other partners in this realm (such as the UN and the OSCE), EU-CIVCAP research also investigates the EU's relations with such actors (see, for instance, Dijkstra et al, this issue; Faleg, this issue).

Finally, by resources we refer to a need to change both material and non-material assets the EU makes available for the purpose of building sustainable peace. Material resources might include financing, technologies, personnel, and equipment provided by the EU or its member states (Pirozzi et al., this issue); non-material resources might include the provision of best practices, doctrines, concepts, progress reports, and other sources of knowledge relevant to the creation and implementation of certain policies. This also includes the creation of new institutions or bodies directly involved in peacebuilding activities (which overlaps with 'rules' above)(see Davis, this issue). EU-CIVCAP researchers also distinguish between general changes in resources for the peacebuilding domain (such as an increase in the EU's aid budget or the procurement of a new technology) and the provision of specific resources for a joint CSDP action or similar crisis/conflict response mission. This latter 
component also involves the provision of resources as determined through contributions by EU member states as well as by the EU budget.

To summarise our approach, experiential institutional learning in the EU context differs from bureaucratic/organisational or individual/cognitive learning, although elements of these approaches do overlap in practice. As noted above, the most important difference is that there is no single EU agency, bureaucracy, or organisation wholly responsible for peacebuilding; instead, this capacity is shared across the EU, involving mainly the Council of the EU, EU member states, the Commission, and the EEAS. Moreover, the EU also developed two distinct approaches to activity in this realm, depending on whether they were primarily military or civilian in nature; EU-CIVCAP researchers focus mainly on the civilian realm but with a view towards civilian-military linkages as one of four important crosscutting issues identified by the project (see below). Therefore, a bureaucratic or organisational approach to learning, which focuses on fairly rigid standard operating procedures or routines (Levitt \& March 1988), would be too narrow to explain the development of these two major EU capabilities (military and civilian), while an individuallevel or cognitive approach to learning would be far too broad if applied to peacebuilding as a general policy domain, ${ }^{6}$ especially as most EU policies in this realm are organised on a caseby-case basis and its mission personnel do not always serve in multiple actions over time. ${ }^{7}$

Thus, if learning is to occur in this domain, given its decentralised bureaucratic structure and rotating operational personnel, it must involve changes within and among the policy units charged with conducting specific policies as they take on new tasks that force them to evaluate, and possibly reform, their normal ways of doing things. Through a focus on the EU's actions in the Balkans and the Horn of Africa in particular, EU-CIVCAP researchers have attempted to identify specific examples where such reforms are needed,

\footnotetext{
${ }^{6}$ For example, Tonra (2003) has applied such an approach to the creation of the CFSP; also see King 2005.

${ }^{7}$ One small exception to this tendency involves the use of 'follow-on' policies to support or extend already existing ones, as they may make use of existing personnel.
} 
which brings us to the lessons identified database (see, for instance, Edmunds et al, this issue; Zartsdahl \& Rodt, this issue). ${ }^{8}$

\section{Lessons identified in EU peacebuilding}

As experience-driven learning involves the generation of shared knowledge to help improve policy performance, the process requires clarity and transparency regarding specific lessons and any best practices that might result from them. Toward this end, EU-CIVCAP has produced an online lessons identified database (or catalogue) that summarises some of the most important findings of the project. It also organises them on the basis of various keywords to make searches easier, grouped into six categories: 1) conflict life cycle stage; 2) policy-making phase; 3) country or region where the lesson was identified; 4) institution(s) involved in the lesson (EU and otherwise); 5) cross-cutting challenges involved (see Juncos \& Blockmans, this issue); and 6) other topics, such as technology or resources (among others) (EU-CIVCAP, 2018).

The online database (or catalogue) of lessons went 'live' in early 2017 and has been populated with 25 lessons identified. Evidence for each of the lessons has been collected from official documents and reports, secondary sources, and dozens of interviews with practitioners in Brussels and in the field. Space considerations prevent a detailed discussion of each of them, but the articles in this Forum identify a number of key lessons. For example, some of them involve conceptual or ideational factors that inspire the EU's overall approach to building sustainable peace. Despite a steadily increasing number of EU reports since the late 1990s about its foreign/security policy strategy, doctrines, concepts, and related ideas, more specific guidance about the EU's fundamental understanding of, and approach to,

\footnotetext{
${ }^{8}$ Institutional learning in the realm of peacebuilding can also be measured in terms of other parameters, such as where the lessons identified appeared in the EU's vertical chain of command (i.e., the strategic/political level, the operational/headquarters level, and the theatre/tactical level); these however are beyond the scope of this article (see Author, 2017a for a more extensive discussion).
} 
conflict tasks in particular is still lacking (Davis, this issue). More guidance here is especially important considering the decentralised, even fragmented, approach to conflict prevention/peacebuilding/crisis management tasks involving a range of actors in Brussels, in EU member states, and in host countries. In this complex system, leadership (or the lack thereof continues to be a recurrent problem (Davis, this issue). The need for new concepts also feeds into other lessons regarding specific rules and procedures to enhance coordination among the Commission, EEAS, EU member states, and other partners/stakeholders involved in peacebuilding through a more integrated approach (Faleg, this issue).

Beyond general concepts and more specific procedures about peacebuilding, a number of other lessons focus on enhancing the material resources available to the EU for such tasks, such as personnel, financing, technology, and other equipment, including resources shared with other partners. These lessons also include insights regarding training practices, the integration of various technologies (such as Big Data, social media, satellites, and drones), and the internal coordination of these resources (Pirozzi et al., this issue), all of which also relate to a set of lessons regarding the EU's evolving concept of its 'comprehensive' or 'integrated' approach to foreign/security policy, which involves applying a full range of resources and policy tools to the full spectrum of security assistance tasks and the conflict life cycle (Faleg, this issue). This set of lessons in turn feeds into other lessons involving the use of different EU instruments (from trade to development aid policies to the CSDP) in the context of peacebuilding tasks as illustrated by the cases of the Western Balkans and the Horn of Africa (Zartsdahl \& Rodt, this issue).

The EU also often works closely with other institutional partners in peacebuilding, such as the UN and NATO, as well as with local stakeholders in host countries, so another set of lessons focuses on these factors in particular, including the goal of more local ownership, regional engagement, and host country capacity-building (Edmunds et al., this issue). The 
need to avoid working as cross-purposes or duplicating effort is a constant challenge in conflict zones, yet despite the EU's years of experience with the UN, NATO, OSCE, AU, and other partners there is still much room for improvement in terms of agreeing on priorities, negotiating the division of labour for specific tasks, and exchanging mission resources (Dijkstra et al., this issue). This need for enhanced coordination also extends to the role of local partners ('local ownership') and host country capacity-building, and the EU should develop clearer guidelines about how to define local owners and then involve them in the planning and implementation phases of peacebuilding tasks (Ejdus \& Juncos, 2018). Finally, such efforts should then enhance the prospects for post-conflict sustainability in a host country once the EU's direct involvement in peacebuilding ends (Edmunds et al., this issue).

\section{Lessons, learning, and institutional change}

The emphasis on learning as a way to facilitate international cooperation is part of a much broader literature on ideational, discursive, and social factors, such as networks, norms, speech acts, expert knowledge, rhetorical action, imitation/demonstration effects, and so on, many of which also find their way into formal institutions once they have demonstrated their potential. Evidence from the articles in this Forum and the wider literature clearly demonstrates that the EU has developed a complex learning culture and that certain lessons have improved the conduct of peacebuilding tasks by the EU and its partners (Orsini 2006; Duke 2009; Flessenkemper \& Helly 2013; Faleg 2016; Author 2017a). However, it is also very clear that there are limits to this approach as a mechanism to reform the EU's institutions and procedures for foreign/security policy cooperation. It is also becoming apparent that a learning approach, by itself, will not suffice in terms of equipping the EU to cope with the range of security problems in its neighbourhood and beyond, or empower the 
EU to fulfil its wider ambitions under the EU Global Strategy (HR/VP 2016).

One problem is that just as peacebuilding is not a single policy domain (nor is crisis response/management more generally), there is no single learning or lessons identified framework to help improve the process. Most significantly, there is a major divide between the civilian and military aspects of peacebuilding, which have their own learning cultures (Pihs-Lang 2013; Author 2017a); this may not only inhibit effective civilian-military coordination but may also may lead to the development of distinct strategic cultures regarding how to conduct various activities. ${ }^{9}$ In addition, lessons identified - whether civilian or military - can be generated from multiple levels of analysis, from the strategic/political level to the operational/planning level to the theatre/host country level. These various levels also involve institutions in Brussels, in EU member states, and in other partners/stakeholders (particularly the UN and NATO), which have their own approaches to learning and which may not mesh with those of the EU. Although the EU has attempted to devise more synergies between them using various coordinating mechanisms, there is still much room for improvement that could involve shared fact-finding missions, planning/deployments, afteraction reviews, best practices, training courses, and so on.

In addition to varied learning approaches throughout the EU's peacebuilding network, a second major problem is that the EU does not always follow its own rules regarding lessons identified. Actors throughout the EU are guilty of such behaviour; this includes the Commission. Such failings can include minor problems (such as neglecting to hold learning meetings or to issue a scheduled learning report, as well as taking longer than expected to issue a report) to major ones (such as neglecting to change a CSDP mission in light of lessons identified)(see European Parliament 2012; Author 2017a). Similarly, as peacebuilding is an

\footnotetext{
${ }^{9}$ Despite the EU's limited experience with major CSDP deployments, especially military ones, there is a longstanding debate in the literature about the advent of an EU strategic culture. For a comprehensive summary see Schmidt \& Zyla 2013. The 2003 European Security Strategy also mentions the need to develop a European strategic culture 'that fosters early, rapid, and where necessary, robust intervention.'
} 
aspect of EU security policy, the problem of transparency in learning procedures also may inhibit a more effective approach to lessons/best practices. Lessons must be shared to be effective, and the EU has not always been forthcoming in terms of how they are generated or applied in specific circumstances. Given these problems, which have been identified in both civilian and military EU networks, the EU's learning culture itself certainly could be enhanced further in terms of more rigorous and consistent procedures across all actors, more central coordination of all EU learning activities, more staff resources for learning activities (particularly the appointment of learning/best practice officers for all peacebuilding missions), and, possibly, the use of outside evaluators or auditors.

A third problem is that the 'mission approach' to peacebuilding tasks, which typically requires the launch of a new CSDP action in a host country to last from several months to several years, often involves the recruitment of new personnel from EU institutions in Brussels and EU member states. Although some degree of staff recruitment and training methods may help to create a certain esprit de corps among these individuals, the fact is that multicultural operations of this type, as well as staff turnover as a mission develops plus the decentralised nature of peacebuilding as a policy domain, can inhibit the kind of 'deep learning' (or cognitive change) that could improve the EU's performance. Some studies have argued that such changes in the CFSP/CSDP may in fact represent a so-called 'epistemic community' in the realm of EU security affairs, which is defined as a distinct network of professionals who rely on the same policy-relevant knowledge base and who share the same views regarding a specific policy domain. Although this might be true in a general sense across a wide range of EU security priorities (i.e. a preference for multilateralism, a focus on prevention with civilian tools, stressing the EU's neighbourhood, and so on; see Howorth 2004 and Cross 2013), other work (Pihs-Lang 2013; Author 2017a) suggests that the EU has not succeeded in building a true shared culture or epistemic community in the CSDP or 
peacebuilding domains. ${ }^{10}$

Finally, even if the problems above could be addressed adequately to improve the EU's overall approach to learning and best practices, they still pale in comparison to the need for ongoing institutional reforms to empower the EU to address the changing security challenges in its own neighbourhood and beyond. The EU has been funding research on conflict prevention, peacebuilding, and related tasks precisely because its current approach has not always produced the desired outcomes, meaning that the EU has not always lived up to its claims as a security provider or as a stabilising force in areas where it claims to have an major interest, such as the Middle East, North Africa, and the eastern borders of the EU itself. In some cases the EU failed to act at all; in others the EU took too long to act to make a real difference (i.e., a failure of rapid crisis response); and in others the EU did act quickly but was not resourced adequately and/or had to scale back its mandate because of factors beyond its control, whether inside or outside of the host country. ${ }^{11}$

The EU Global Strategy (HR/VP 2016) attempts to address some of these problems in terms of general principles (such as an emphasis on resilience in host countries), yet it does not address a number of critical structural issues that inhibit the EU's capacity for crisis response and security assistance. Perhaps the most important such structural problem is that for all of its bureaucratic and legal complexity, the EU is still a treaty-based international organisation composed of sovereign states, many of which have their own views about security policy, conflict prevention, and peacebuilding. As EU member states still retain a high degree of authority in those domains, and are wary of delegating greater authority to EU institutions in Brussels, they can - and have - often prevented the EU from acting more

\footnotetext{
${ }^{10}$ The same can be said of attitudes among new staff members of the EEAS; see Spence 2012; Juncos \& Pomorska 2013; and Juncos \& Pomorska 2014.

${ }^{11}$ For examples of such assessments, see Grevi, Helly \& Keohane 2009; Dijkstra 2010; Gowan 2011; Haine 2011; Juncos 2013; Engberg 2014; Author 2017a.
} 
forcefully for a variety of reasons that have nothing to do with security policy and conflict prevention. $^{12}$

\section{Conclusion}

The EU has made significant advances in the realm of peacebuilding through the CFSP/CSDP mechanisms and other policy tools. In less than 15 years the EU has launched over 30 CSDP foreign security assistance actions, many of which involve conflict management goals, and has developed a range of strategies, concepts, guidelines, and other policy statements to guide its ambitions as a conflict manager and peacekeeper. Our emphasis in this Forum has been on the politics and practice of EU peacebuilding activity, viewing it not as an ideal type or distinct EU policy domain but as an arena for political contestation within and among key stakeholders in Brussels, host countries, EU member states, and major EU partners. Part of this ongoing contestation also involves the generation of potential lessons and best practices in this realm, which EU-CIVCAP has attempted to document through the methodology discussed in this article.

However, there is still much room for improvement for the reasons discussed above involving the overall coherence, management, and resourcing of EU peacebuilding activities (Pirozzi et al., this issue), different institutional approaches to learning, erratic compliance with agreed learning procedures, the varied roles of numerous stakeholders in a complex decentralised system, the use of veto points by EU member states during decision-making, various cross-cutting challenges (Juncos \& Blockmans, this issue), and other factors. Moreover, even when learning has helped to develop and resource new foreign security actions, the comprehensive or integrated approach to crisis response is often still lacking, whether in terms of linking civilian and military policy tools or linking the EU's (shorter-

${ }^{12}$ Such as domestic politics; see Pohl 2014. 
term) security/conflict prevention agenda with its (longer-term) development/humanitarian agenda (Coning \& Friis 2011; Author 2017a; Davis, this issue; Faleg, this issue; Zartsdahl \& Rodt, this issue). The EU's failure to live up to the integrated approach in turn makes it seem as if the EU is not a proactive strategic actor capable of shaping events but rather merely a reactive bit player that offers a token contribution in certain host countries before moving on to the next crisis.

The EU therefore must be not just more coherent, comprehensive, proactive, and strategic but also far more realistic in terms of what it can achieve and why it is attempting to achieve it. And it must be prepared to explain these decisions more effectively to European citizens, especially if the programmes fail or if EU citizens are harmed/killed when running them. Thus, although the EU has made significant advances in the peacebuilding domain, and has built upon this experience through the creation of policy-relevant knowledge about conflict and crisis management, it does not always manage to meet the growing demand for decisive security assistance actions, especially on its borders. This is not for a lack of resources; the EU (with its member states) possesses the human capital, knowledge base, and material/technological tools to act like other major powers in many peacebuilding areas, yet it still falls short in this area because of the various factors discussed in this Forum and in the research it draws upon. Hopefully future such investigations will help empower the EU in terms of choosing its strategic priorities, streamlining its decision-making procedures (in Brussels and in EU member states), and resourcing its foreign security missions adequately and quickly, whether in the civilian or military spheres. In today's world there is unfortunately no shortage of opportunities for the EU to get more involved in conflict resolution and crisis management; the only question is whether the EU can find the political will - in Brussels and among its member states - to make the reforms suggested by the considerable body of research it has funded in this area. 


\section{Bibliography}

Bickerton, C.J., D. Hodson and U. Puetter (eds.)(2015), The New Intergovernmentalism: States and Supranational Actors in the Post-Maastricht Era, Oxford: Oxford University Press.

Coning, C., and K. Friis (2011), 'Coherence and coordination: The limits of the comprehensive approach', Journal of International Peacekeeping 15(1): 243-72.

Cross, M.D. (2013), Security Integration in Europe: How Knowledge-Based Networks are Transforming the European Union, Ann Arbor: University of Michigan Press.

Davis, L. (this issue). 'Betwixt and between: Conceptual and practical challenges of preventing violent conflict through EU external action'. Global Affairs.

Dijkstra, H. (2010), 'The military operation of the EU in Chad and the Central African Republic: Good policy, bad politics', International Peacekeeping 17: 395-407.

Dijkstra, H., E. Mahr, P. Petrov, K. Đokić \& P.H. Zartsdahl (this issue), 'The EU's partners in crisis response and peacebuilding: Complementarities and synergies with the UN and OSCE'. Global Affairs.

Duke, S. (2009), 'Consensus-building in ESDP: The lessons of operation Artemis', International Politics 46: 395-412.

Edmunds, T., A.E. Juncos \& G. Algar-Faria (this issue), 'EU local capacity building and the problem of ownership', Global Affairs.

Engberg, K. (2014), The EU and Military Operations: A Comparative Analysis. Abingdon: Routledge.

EU-CIVCAP (2018), Catalogue of Lessons Identified, available at https://eucivcap.net/lessons/ [last accessed 1 March 2018].

European Parliament (2012), 'CSDP Missions and Operations: Lessons Learned Processes', EXPO/B/SEDE/FWC/2009-01/Lot6/16, April [accessed 8 May 2017], available from: http://www.europarl.europa.eu/RegData/etudes/etudes/join/2012/457062/EXPOSEDE_ET(2012)457062 EN.pdf.

Faleg, G. (2016), The EU's Common Security and Defence Policy: Learning Communities in International Organisations. Basingstoke: Palgrave.

Faleg, G. (this issue), 'The EU's integrated approach: Analysis and comparison with the UN, NATO and the OSCE', Global Affairs.

Flessenkemper, T., and D. Helly (eds)(2013), Ten Years After: Lessons of the EUPM in Bosnia and Herzegovina. Paris: EUISS.

Gowan, R. (2011), 'From rapid reaction to delayed inaction? Congo, the UN and the EU', International Peacekeeping 18/5 (November): 593-611. 
Grevi, G., D. Helly, and D. Keohane (eds)(2009), European Security and Defence Policy: The First 10 Years. Paris: EU Institute for Security Studies.

Haine, J.Y. (2011), 'The failure of a European strategic culture - EUFOR Tchad: The last of its kind?' Contemporary Security Policy 32: 494-516.

Haas, E.B. (1990), When Knowledge Is Power: Three Models of Change in International Organizations. Berkeley: University of California Press.

High Representative of the EU (HR/VP) (2016) 'Shared vision, common action: A stronger Europe. A Global Strategy for the European Union's Foreign and Security Policy', June 2016. Available from:

http://europa.eu/globalstrategy/sites/globalstrategy/files/pages/files/eugs_review_web_13.pdf [Accessed 1 November 2017].

Howorth, J. (2004), 'Discourse, ideas, and epistemic communities in European Security and Defence Policy', West European Politics, 27(2), 211-43.

Juncos, A.E. (2013), EU Foreign and Security Policy in Bosnia: The Politics of Effectiveness and Coherence. Manchester: Manchester University Press.

Juncos, A.E. and S. Blockmans (this issue), 'European Union civilian capabilities for peacebuilding: Key Challenges', Global Affairs.

Juncos, A.E. and K. Pomorska (2014), 'Manufacturing "esprit de corps": The case of the European External Action Service', Journal of Common Market Studies 52: 302-19.

Juncos, A.E. and K. Pomorska (2013), "'In the face of adversity": Explaining the attitudes of EEAS officials vis-à-vis the new service', Journal of European Public Policy 20: 1332-49.

King, A. (2005), 'The future of the European Security and Defence Policy', Contemporary Security Policy, 26(1), 44-61.

Levitt, B. and J.G. March (1988), 'Organizational learning', Annual Review of Sociology, 14(1), 319-38.

Levy, J.S. (1994), 'Learning and foreign policy: Sweeping a conceptual minefield', International Organization, 48(2), 279-312.

Lipson, C. (1984), 'International Cooperation in Economic and Security Affairs', World Politics, 37(1), 1-23.

Nováky, N.I.M. (2015), 'Deploying EU crisis management operations: A collective action perspective', European Security, 24(4), 491-508.

Øhrgaard, J.C. (1997), "'Less than supranational, more than intergovernmental:" European Political Cooperation and the dynamics of intergovernmental integration', Millennium: Journal of International Studies, 26(1), 1-29. 
Orsini, D. (2006), 'Future of ESDP: Lessons from Bosnia', European Security Review 29: $1-5$.

Paris, R. and T.D. Sisk (eds)(2009), The Dilemmas of Statebuilding: Confronting the Contradictions of Postwar peace operations. London: Routledge.

Pihs-Lang, S. (2013), Lessons (Not) Learned? EU Military Operations and the Adaptation of CSDP. PhD thesis, European University Institute (Florence, Italy).

Pirozzi, N., B. Venturi, and A. Marrone (this issue), 'EU Member States' capabilities in conflict prevention and peacebuilding: Personnel and technologies', Global Affairs.

Pohl, B. (2014), EU Foreign Policy and Crisis Management Operations: Power, Purpose, and Domestic Politics. Abingdon: Routledge.

Schmidt, P., and B. Zyla (eds)(2013), European Security Policy and Strategic Culture. Abingdon: Routledge.

Spence, D. (2012), 'The early days of the European External Action Service: A practitioner's point of view', The Hague Journal of Diplomacy 7: 115-34.

Tonra, B. (2003), 'Constructing the Common Foreign and Security Policy: The utility of a cognitive approach', Journal of Common Market Studies, 41(4), 731-76.

UN and EU (2003), 'Joint Declaration on EU-UN Cooperation in Crisis Management', 12510/03 (Presse 266), 24 September [accessed 8 May 2017], available from: http://www.consilium.europa.eu/uedocs/cms_data/docs/pressdata/en/misc/77348.pdf.

UN Peacekeeping Best Practices Unit (2004), Operation Artemis: The Lessons of the Interim Emergency Multinational Force, New York: UN.

Weiss, M. (2012), 'Transaction costs and the establishment of the European Security and Defence Policy', Security Studies, 21(4), 654-82.

Zartsdahl, P. \& A.P. Rodt (this issue), 'Assessing the implementation of EU's Comprehensive Approach: A comparative case study of Western Balkans and the Horn of Africa', Global Affairs.

Zito, A.R. (2009), 'European agencies as agents of governance and learning', Journal of European Public Policy, 16(8), 1224-43.

Zito, A.R. and A. Schout (2009), 'Learning theory reconsidered: EU integration theories and learning', Journal of European Public Policy, 16(8), 1103-23. 